\title{
Profile and reproductive roles of seminal plasma melatonin of boar ejaculates used in artificial insemination programs ${ }^{1}$
}

\author{
I. Barranco,* A. Casao, $\dagger$ C. Perez-Patiño,* I. Parrilla,* \\ T. Muiño-Blanco, $\dagger$ E. A. Martinez,* J. A. Cebrian-Perez, $\uparrow$ and J. Roca*2 \\ *Department of Medicine and Animal Surgery, Faculty of Veterinary \\ Science, University of Murcia, Murcia 30100, Spain; and †Department of Biochemistry \\ and Molecular and Cell Biology, Faculty of Veterinary Medicine, University of Zaragoza, Zaragoza 50013, Spain
}

\begin{abstract}
Melatonin (MLT) is present in seminal plasma (SP) of mammalian species, including pigs, and it is credited with antioxidant properties. This study aims to identify the sources of variation and the role of boar SP MLT on sperm quality and functionality and in vivo fertilizing ability of liquid-stored semen doses used in AI programs. The SP MLT was measured using an ELISA kit in a total of 219 ejaculates collected from 76 boars, and reproductive records of 5,318 AI sows were recorded. Sperm quality was assessed according to motility (computer-aided sperm analysis) and viability (cytometry evaluation). Sperm functionality was assessed according to the cytometric determination of intracellular $\mathrm{H}_{2} \mathrm{O}_{2}$ generation, total and mitochondrial $\mathrm{O}_{2}^{-}$production, and lipid peroxidation in liquid AI semen samples stored at $17^{\circ} \mathrm{C}$ over $144 \mathrm{~h}$. The concentration of SP MLT differed among seasons $(P<0.01)$ and day length periods $(P<0.001)$ of the year, demonstrating that the ejaculates collected during the increasing day length period $(9.80 \pm 1.38 \mathrm{pg} /$
\end{abstract}

$\mathrm{mL}$, range: 2.75-21.94) had lower SP MLT concentrations than those collected during the decreasing day length period $(16.32 \pm 1.67 \mathrm{pg} / \mathrm{mL}$, range: $5.02-$ 35.61). The SP MLT also differed $(P<0.001)$ among boars, among ejaculates within boar, and among portions within the ejaculate, demonstrating that SP from the first $10 \mathrm{~mL}$ of sperm-rich ejaculate fraction (SRF) exhibited lower MLT concentrations than post-SRF. The SP MLT was negatively related $(P<0.001)$ to mitochondrial $\mathrm{O}_{2}^{-}$production in viable sperm. The SP MLT did not differ among AI boars $(n=14)$ hierarchically grouped according to high and low fertility outcomes. In conclusion, SP MLT concentration in AI boars varies depending on the season of ejaculate collection and differs among boars, ejaculates within boar, and portions within ejaculate. The SP MLT may act at the mitochondrial level of sperm by reducing the generation of $\mathrm{O}_{2}^{-}$. However, this antioxidant role of SP MLT was not reflected in sperm quality or in vivo fertility outcomes of AI semen doses.

Key words: boar, fertility, melatonin, seminal plasma, sperm

(C) 2017 American Society of Animal Science. All rights reserved.

J. Anim. Sci. 2017.95:1660-1668 doi:10.2527/jas2016.1286

\section{INTRODUCTION}

\footnotetext{
${ }^{1}$ Financial support for this research was provided by MINECO (Madrid, Spain) and FEDER (EU) grants (AGL2012-39903, AGL2013-43328-P, and AGL2015-69738-R) and Seneca Foundation (19892/GERM/15) Murcia (Spain). I. Barranco and C. PerezPatiño were financially supported by MECD (Madrid, Spain) and the Seneca Foundation (Murcia, Spain), respectively. The authors are grateful to AIM Iberica (Topigs Norsvin Iberica) for supplying the boar ejaculates and fertility records.

${ }^{2}$ Corresponding author: roca@um.es

Received December 7, 2016.

Accepted January 27, 2017.
}

Melatonin (MLT) regulates body physiological actions related to circadian rhythms, including reproductive activity in seasonal breeders (Reiter et al., 2009). In addition to the pineal gland, MLT is also synthesized in other tissues, including testes (Reiter et al., 2000; González-Arto et al., 2016a). Consequently, MLT is present in seminal plasma (SP), as evidenced in man (Van Vuuren et al., 1988) and in livestock males, including boars (González-Arto et al., 2016b). In addition to highlighting its presence and seasonal pattern exhibited in seasonal breeders (Casao et al., 2010a), 
little more is currently known about SP MLT. The present study tries to improve the knowledge of SP MLT, particularly its biological profile and functional roles in sires used in AI, specifically boars. Despite this lack of knowledge, MLT is widely used as an additive in both semen extenders (Jang et al., 2010; Ashrafi et al., 2011) and media for in vitro fertilization (Pang et al., 2016) and embryo development (Papis et al., 2007), because it has recognized antioxidant properties when used as a therapeutic agent against some functional disorders occurring in serious human diseases such as cancer or aging (Bonnefont-Rousselot and Collin, 2010; Karaaslan and Suzen, 2015). Therefore, this study will focus mainly on the investigation of the putative antioxidant properties of SP MLT, evaluating its impact on quality and sperm functionality. Some SP components with antioxidant capacities, such as glutathione peroxidase- 5 and paraoxonase 1 , have shown a direct relationship with in vivo fertility outcomes of boar semen AI doses (Novak et al., 2010; Barranco et al., 2015, 2016). Accordingly, the study also aims to evaluate whether SP MLT is associated with the in vivo fertility of boar semen doses used in commercial AI programs. To achieve these aims, semen and SP samples from 219 ejaculates, collected from 76 AI boars, and fertility records of 5,318 AI sows were evaluated.

\section{MATERIALS AND METHODS}

\section{Reagents and Media}

All chemicals used in the experiments were of analytical grade. Unless stated otherwise, all media components were purchased from Sigma-Aldrich (St. Louis, MO), and the media were prepared under sterile conditions in a laminar flow chamber (MicroH; Telstar, Terrassa, Spain). Fluorochrome molecules were purchased from Molecular Probes Europe BV (Leiden, the Netherlands).

The basic medium used for semen extension was Beltsville thawing solution (BTS) composed of $205 \mathrm{mM}$ glucose, $20.4 \mathrm{~m} M$ sodium citrate, $10.0 \mathrm{mM} \mathrm{KCl}, 15.0$ $\mathrm{m} M \mathrm{NaHCO}_{3}$, and $3.6 \mathrm{~m} M$ EDTA, pH 7.2, and 290 to $300 \mathrm{mOsmol} / \mathrm{kg}$ supplemented with kanamycin sulfate $(0.05 \mathrm{mM})$. Ethylenediaminetetraacetic acid-free PBS (139 $\mathrm{m} M \mathrm{NaCl}, 2.7 \mathrm{~m} M \mathrm{KCl}, 1.5 \mathrm{~m} M \mathrm{KH}_{2} \mathrm{PO}_{4}$, and 8.1 $\mathrm{mM} \mathrm{Na} 2 \mathrm{HPO}_{4} \cdot 7 \mathrm{H}_{2} \mathrm{O}$ with $0.058 \mathrm{~g} / \mathrm{L}$ penicillin $\mathrm{G}$ and $0.05 \mathrm{~g} / \mathrm{L}$ streptomycin sulfate; $\mathrm{pH} 7.1 ; 285-290$ mOs$\mathrm{mol} / \mathrm{kg}$ ) was used to extend the semen samples and dilute fluorochromes for flow cytometric analysis.

\section{Boars and Ejaculates}

All procedures that involved animals were performed according to international guidelines (directive 2010-63EU; European Parliament and the Council of the European
Union, 2010) and approved by the Bioethics Committee of Murcia University (research code 639/2012).

All ejaculates were obtained in the afternoon, between 1400 and $2000 \mathrm{~h}$, from healthy, sexually mature boars of different breeds (Landrace, Large White, and Pietrain) or crossbreeds (Landrace $\times$ Large White) undergoing regular semen collection (an average of an ejaculate every $3 \mathrm{~d}$ ) for commercial AI purposes. Boars $(n=76)$ were housed in 4 Spanish AI centers belonging to AIM Ibérica (Topigs Norsvin España, Madrid, Spain) and located in Leon $\left(42^{\circ} 25^{\prime} \mathrm{N}, 5^{\circ} 31^{\prime} \mathrm{W}\right)$, Lerida $\left(41^{\circ} 42^{\prime}\right.$ $\left.\mathrm{N}, 0^{\circ} 42^{\prime} \mathrm{E}\right)$, Murcia $\left(38^{\circ} 15^{\prime} \mathrm{N}, 1^{\circ} 35^{\prime} \mathrm{W}\right)$, and Soria $\left(41^{\circ} 43^{\prime} \mathrm{N}, 2^{\circ} 11^{\prime} \mathrm{W}\right)$. The boars were subjected to the same housing and management conditions, specifically individual pens in environmentally controlled $\left(15-25^{\circ} \mathrm{C}\right)$ buildings with windows such that they were exposed to natural daylight and supplementary light for a total of $16 \mathrm{~h}$ of light per day ( $\geq 150 \mathrm{~lx}$ of light intensity at boar eye level). They were provided with ad libitum access to water and were fed commercial feedstuff according to nutritional requirements for adult AI boars. The ejaculates that were used fulfilled the standards of quantity and sperm quality thresholds for the preparation of semen AI doses (greater than $200 \times 10^{6}$ sperm $/ \mathrm{mL}, 70 \%$ motile spermatozoa, and $75 \%$ of morphologically normal cells).

\section{Seminal Plasma Processing and Storage}

The SP samples were obtained immediately after ejaculate collection through double centrifugation $(1,500 \times g$ for $10 \mathrm{~min}$ at room temperature; Rotofix 32A; Hettich Centrifuge UK, Newport Pagnell, Buckinghamshire, England, UK) of $15 \mathrm{~mL}$ of the semen sample. The second supernatant was harvested and examined by microscopy (Eclipse E400; Nikon, Tokyo, Japan) to ensure the absence of sperm. Then, SP samples were stored in cryotubes and sent in insulated containers with dry ice to the Andrology Laboratory at the Veterinary Teaching Hospital of the University of Murcia (Spain). At the laboratory, the SP samples were stored at $-80^{\circ} \mathrm{C}$ (Ultra Low Freezer; Haier Inc., Qingdao, China) until MLT analysis. For analyses, the SP samples were thawed at room temperature inside a dark chamber where they remained for $60 \mathrm{~min}$.

\section{Measurement of Melatonin Concentration}

The measurement of the concentration of MLT that was present in the SP samples was performed in the Department of Biochemistry and Molecular and Cell Biology of the University of Zaragoza (Spain) using a commercial competitive immunoassay (direct saliva melatonin ELISA kit; Bühlmann Laboratories AG, Schönenbuch, Switzerland; $0.5 \mathrm{pg} / \mathrm{mL}$ sensitivity and 
$5.2 \%$ intra-assay variability) following the manufacturer's instructions. Briefly, $100 \mu \mathrm{L}$ of each SP sample, controls, and calibrator was added in duplicate in a microtiter plate coated with an anti-MLT antibody and incubated for 16 to $20 \mathrm{~h}$ at 2 to $8^{\circ} \mathrm{C}$. Controls include known high and low MLT concentrations for a range of values between 1.9 and $21.9 \mathrm{pg} / \mathrm{mL}$. After incubation, $50 \mu \mathrm{L}$ of biotinylated MLT was added to each well and incubated for $3 \mathrm{~h}$ at 2 to $8^{\circ} \mathrm{C}$. After 3 washes, $100 \mu \mathrm{L}$ of streptavidin conjugated to horseradish peroxidase was loaded to the wells and incubated for $60 \mathrm{~min}$ in a plate rotator set at $600 \mathrm{rpm}$ at 18 to $28^{\circ} \mathrm{C}$. Then, the wells were washed 3 times, and $100 \mu \mathrm{L}$ of tetramethylbenzidine substrate was added to each well and incubated in the dark for 30 min on a plate rotator at $600 \mathrm{rpm}$ and 18 to $28^{\circ} \mathrm{C}$. After incubation, $100 \mu \mathrm{L}$ of $0.25 \mathrm{M} \mathrm{H}_{2} \mathrm{SO}_{4}$ solution was added, and absorbance was measured on a microtiter plate reader (TECAN Spectrafluor plus; Tecan Schweiz AG, Männedorf, Switzerland) at $450 \mathrm{~nm}$. The SP concentration of MLT was expressed in picograms per milliliter.

\section{Assessment of Sperm Quality and Functionality}

The spermatozoa were assessed according to quality (total and progressive motility and viability) and functionality (intracellular $\mathrm{H}_{2} \mathrm{O}_{2}$ generation, mitochondrial $\mathrm{O}_{2}^{-}$production, total sperm $\mathrm{O}_{2}^{-}$production, and lipid peroxidation) parameters. All of these assessments, except motility, which was evaluated using a computerassisted sperm analyzer (CASA), were performed by flow cytometry using a BD FACS Canto II flow cytometer (Becton, Dickinson and Company, Franklin Lakes, NJ). Hoechst 33342 (H-42) staining (DNA content) was used to identify sperm events. Acquisition was stopped after 10,000 H-42-positive events.

Sperm motility was objectively evaluated using an ISASv1 CASA (Proiser R+D S.L., Paterna, Spain). Briefly, $5 \mu \mathrm{L}$ of extended semen $\left(10 \times 10^{6}\right.$ to $30 \times 10^{6}$ sperm $/ \mathrm{mL}$ in BTS $)$ were placed in a prewarmed $\left(38^{\circ} \mathrm{C}\right)$ Makler counting chamber (Sefi Medical Instruments Ltd., Haifa, Israel). Six to 9 fields with a minimum of 400 spermatozoa per sample were microscopically analyzed (200x). The variables that were recorded were the overall percentage of motile spermatozoa (average path velocity $\geq 20 \mu \mathrm{m} / \mathrm{s}$ ) and the proportion of motile spermatozoa showing rapid and progressive movement (straight line velocity $\geq 40 \mu \mathrm{m} / \mathrm{s}$ ).

For sperm viability assessment, $100 \mu \mathrm{L}$ of semen $\left(30 \times 10^{6} \mathrm{sperm} / \mathrm{mL}\right.$ in BTS $)$ were mixed with $3 \mu \mathrm{L}$ of $\mathrm{H}-42(0.05 \mathrm{mg} / \mathrm{mL}$ in PBS $), 2 \mu \mathrm{L}$ of propidium iodide (PI; $0.5 \mathrm{mg} / \mathrm{mL}$ in PBS), and $2 \mu \mathrm{L}$ of fluorescein-conjugated peanut agglutinin (PNA-FITC; $100 \mu \mathrm{g} / \mathrm{mL}$ in PBS) and then incubated at $38^{\circ} \mathrm{C}$ in the dark for 10 min. Immediately before analysis, $400 \mu \mathrm{L}$ of PBS was added to each sample. Viable spermatozoa were those exhibiting intact plasma and acrosome membranes (H-42 positive, PI negative, and PNA-FITC negative) and data were reported as percentages.

The intracellular generation of $\mathrm{H}_{2} \mathrm{O}_{2}$ was measured in viable spermatozoa using 5- (and 6-) chloromethyl-20,70-dichlorodihydrofluorescein diacetate acetyl ester (CM-H2DCFDA). For each semen sample, $50 \mu \mathrm{L}$ of extended spermatozoa $\left(30 \times 10^{6}\right.$ sperm/ $\mathrm{mL}$ in BTS) was resuspended in $950 \mu \mathrm{L}$ of PBS containing $1.25 \mu \mathrm{L}$ of $\mathrm{H}-42(0.05 \mathrm{mg} / \mathrm{mL}$ in PBS $), 1 \mu \mathrm{L}$ of PI $\left(0.5 \mathrm{mg} / \mathrm{mL}\right.$ in PBS), and $1 \mu \mathrm{L}$ of CM-H ${ }_{2}$ DCFDA ( 1 $\mathrm{m} M$ in dimethyl sulfoxide [DMSO]) to measure basal $\mathrm{H}_{2} \mathrm{O}_{2}$ generation. The samples were incubated at $38^{\circ} \mathrm{C}$ in the dark for $30 \mathrm{~min}$ before flow cytometric analysis. Data were recorded as the percentage of viable (H-42 positive and PI negative) 2',7'-dichlorodihydrofluorescein diacetate $\left(\mathbf{H}_{2}\right.$ DCFDA)-positive spermatozoa.

Mitochondrial $\mathrm{O}_{2}{ }^{-}$production was assessed using MitoSOX Red (MSR) following a modified Koppers et al. (2008) procedure. MitoSOX Red is a lipid soluble cation that selectively targets the mitochondrial matrix, where it is oxidized by $\mathrm{O}_{2}{ }^{-}$and exhibits a red fluorescence. Briefly, an MSR stock solution ( $5 \mathrm{mM}$ in DMSO) was diluted in PBS $(0.5 \mathrm{mM})$, and $5 \mu \mathrm{L}$ was added to $1 \mathrm{~mL}$ of each semen sample $\left(10 \times 10^{6}\right.$ sperm $/ \mathrm{mL}$ ), which were incubated for $15 \mathrm{~min}$ at $37^{\circ} \mathrm{C}$. Thereafter, the samples were centrifuged for $5 \mathrm{~min}$ at $600 \times g$ at room temperature, and the sperm pellets were diluted in PBS at $10 \times 10^{6} \mathrm{sperm} / \mathrm{mL}$. Then, $10 \mu \mathrm{L}$ of SYTOX Green ( $5 \mu M$ in DMSO; Sigma) and $15 \mu \mathrm{L}$ of $\mathrm{H}-42(0.05 \mathrm{mg} / \mathrm{mL}$ in PBS$)$ were added to 1 $\mathrm{mL}$ of each semen sample, which were incubated for $15 \mathrm{~min}$ at $37^{\circ} \mathrm{C}$. Semen samples were diluted in PBS $(1: 2, \mathrm{vol} / \mathrm{vol})$ before flow cytometry analysis. Data were recorded as percentage of viable (H-42 positive/ SYTOX Green negative) MSR-positive spermatozoa.

Total sperm $\mathrm{O}_{2}^{-}$production was assessed using dihydroethidium (DHE) following a modification of the procedure described by Koppers et al. (2008). Dihydroethidium is a permeable molecule susceptible to oxidation inside sperm by $\mathrm{O}_{2}^{-}$, producing 2 DNAsensitive fluorochromes, ethidium and 2-hydroxyethidium, that generate red nuclear fluorescence. Briefly, $10 \mu \mathrm{L}$ of DHE (200 $\mu M$ in DMSO) was added to $1 \mathrm{~mL}$ of each semen sample $\left(10 \times 10^{6}\right.$ sperm $\left./ \mathrm{mL}\right)$, which were incubated for $15 \mathrm{~min}$ at $37^{\circ} \mathrm{C}$. Then, $10 \mu \mathrm{L}$ of SYTOX Green ( $5 \mu M$ in DMSO) and $15 \mu \mathrm{L}$ of H-42 $(0.05 \mathrm{mg} /$ $\mathrm{mL}$ in PBS) were added to $1 \mathrm{~mL}$ of each semen sample, which were incubated for $15 \mathrm{~min}$ at $37^{\circ} \mathrm{C}$. Then, the samples were centrifuged for $5 \mathrm{~min}$ at $600 \times g$ at room temperature, and the sperm pellets were diluted in PBS until a 1-mL sample remained. Semen samples were diluted in PBS (1:2, vol/vol) before flow cytometry analysis. Data 
were recorded as the percentage of viable (H-42 positive/ SYTOX Green negative) DHE-positive spermatozoa.

Lipid peroxidation was assessed using C11 Boron-dipyrromethene 581/591 (BODIPY) following a modification of the procedure described by Silva and Gadella (2006). The BODIPY (5 $\mu M$ in ethanol) was added to $10 \times 10^{6} \mathrm{sperm} / \mathrm{mL}$, incubated for 30 $\min$ at $37^{\circ} \mathrm{C}$, and washed once $(300 \times g$ for $7 \mathrm{~min}$ at room temperature). Then, $100 \mu \mathrm{L}$ of each sample were mixed with $2 \mu \mathrm{L}$ of $\mathrm{H}-42(0.05 \mathrm{mg} / \mathrm{mL}$ in PBS $)$ plus $1.3 \mu \mathrm{L}$ of PI $(0.5 \mathrm{mg} / \mathrm{mL}$ in PBS $)$ and incubated for $10 \mathrm{~min}$ at $37^{\circ} \mathrm{C}$. Two hundred microliters of PBS was added to each sample before flow cytometry analysis. Data were recorded as percentage of viable (H-42 positive and PI negative) BODIPY-positive spermatozoa.

\section{Experimental Design}

Experiment 1: Seasonality in Boar Seminal Plasma Melatonin Concentration. A total of 48 ejaculates from 6 boars ( 8 ejaculates per boar) were collected using a semiautomatic collection method (Collectis; IMV Technologies, L'Aigle, France) during the seasons of the year ( 2 ejaculates per boar per season) as identified in the northern hemisphere-winter (January-March), spring (April-June), summer (JulySeptember), and autumn (October-December) - over $1 \mathrm{yr}$. The resulting SP samples were grouped according to 1) the season of the year and 2) the 2 day length periods of the year (increasing [January-June] and decreasing [July-December] day length periods).

Experiment 2: Variability of Seminal Plasma Melatonin Concentration among Boars, Ejaculates, and Ejaculate Portions. To evaluate the variability among boars (interboar variability) and within the same boar (intraboar variability), MLT concentrations were measured in SP samples from 84 entire ejaculates of 21 boars (4 ejaculates per boar). Ejaculates were collected during the increasing (10 boars, 40 ejaculates) and decreasing (11 boars, 44 ejaculates) day length periods of the year.

To evaluate intraejaculate variability, SP MLT concentration was measured in SP samples from 15 ejaculates of 5 boars ( 3 ejaculates per boar) collected during the increasing day length period of the year. The ejaculates were collected using the regular gloved-hand method to separately collect 3 ejaculate portions, specifically the first $10 \mathrm{~mL}$ of sperm-rich ejaculate fraction (SRF) and the remaining SRF and the post-SRF.

Experiment 3: Relationship between Seminal Plasma Melatonin Concentration and Quality and Sperm Functionality of Liquid-Stored Semen AI Doses. A total of 30 entire ejaculates (1 per boar) were used to produce semen AI doses (semen samples diluted to $30 \times$
$10^{6} \mathrm{sperm} / \mathrm{mL}$ in Biosem + extender; Magapor, Zaragoza, Spain) and to generate SP samples for MLT measurement. The semen AI doses were stored for $144 \mathrm{~h}$ at 15 to $17^{\circ} \mathrm{C}$ (FOC $120 \mathrm{E}$ Cooled Incubator; VELP Scientifica, Usmate, Italy), and sperm quality and functionality were evaluated at 24,72 , and $144 \mathrm{~h}$ of storage.

Experiment 4: Relationship between Seminal Plasma Melatonin Concentration and In Vivo Fertility of Liquid-Stored Semen AI Doses. Semen AI doses, as described in Exp. 3, and SP samples from entire ejaculates collected from 14 boars during the decreasing day length period were used in the experiment. Semen AI doses $\left(2,400 \times 10^{6}\right.$ of total sperm in $\left.80 \mathrm{~mL}\right)$ were used to cervically inseminate (2-3 times per estrus) weaned multiparous (1-7 litters produced) Landrace and Large White sows housed in different farms in Spain. The sows were subjected to the same housing and management conditions regardless of the farm. The number of AI sows per boar ranged between 104 and 814 . Fertility parameters were recorded in terms of farrowing rate (as a proportion of the number of sows inseminated) and litter size (as the sum of alive and dead piglets born per litter). Three SP samples, separated in time from each boar, were used to measure the MLT concentration.

\section{Statistical Analysis}

Data were analyzed using IBM SPSS Statistics 19.0 (IBM España S. A., Madrid, Spain). Residual data for each statistical variable were evaluated using the Kolmogorov-Smirnov test to check the assumption of normality, and data that were not normally distributed were arcsine- (data expressed as a percent) or log- (count data) transformed. In Exp. 1, 1-way ANOVA was performed to evaluate the influence of the season and day length period of the year on SP MLT concentration. In Exp. 2, a mixed ANOVA model, including the effects of boar and ejaculate within boar, was performed to evaluate the inter- and intraboar variability on SP MLT concentration, and intraboar reliability was assessed by intraclass correlation (ICC; $(3,1))$ using a 2-way mixed approach. Differences among ejaculate portions in SP MLT concentration were assessed using 1-way ANOVA. In Exp. 3, hierarchical cluster analysis was performed to identify naturally occurring groups within the data set of SP MLT, and 2 groups (high and low SP concentration of MLT) were identified. Repeated-measures ANOVA was performed to evaluate the influence of the SP MLT group and storage time $(24,72$, and $144 \mathrm{~h})$ on quality and sperm functionality parameters. In Exp. 4, the raw fertility data set was initially corrected for parameters related to farm and sow using a multivariate statistical model (Broekhuijse et al., 2012) to specifically identify the effect of boar on both fertility parameters: farrowing 


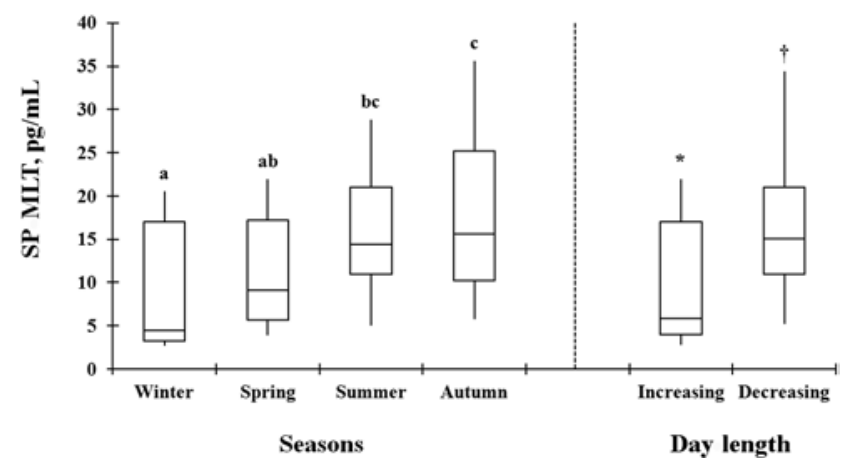

Figure 1. Box-and-whisker plot showing the concentration of melatonin (MLT) present in the seminal plasma (SP) of boar ejaculates collected during different seasons (on the left) and day length periods of the year (increasing and decreasing; on the right) of the northern hemisphere. Boxes enclose the 25th and 75th percentiles. The line represents the median; the whiskers extend to the 5 th and 95 th percentiles. ${ }^{\text {a-c }}$ Different superscripts indicate significant differences $(P<0.01)$ among the seasons, and ${ }^{*}, \dagger$ indicate significant differences $(P<0.001)$ between the 2 day length periods of the year.

rate and litter size. Then, 2 hierarchical cluster analyses were performed to identify naturally occurring groups among boars according to both fertility parameters, and 2 groups of boars exhibiting high and low farrowing rates and another 2 groups exhibiting large and small litter sizes were identified. One-way ANOVA was performed to investigate differences on SP MLT among boar groups. The Bonferroni test was used for post hoc analyses where appropriate. Statistical significance was defined as $P<$ 0.05 . Data are presented as the means $\pm \mathrm{SEM}$.

\section{RESULTS}

\section{Experiment 1: Seasonality in Seminal Plasma Melatonin Concentration}

The season of ejaculate collection influenced $(P<$ $0.01)$ the SP concentration of MLT, demonstrating that the ejaculates collected during winter and spring exhibited the lowest MLT concentrations and those collected during autumn exhibited the greatest MLT concentrations. Consequently, the day length period of the ejaculate collection also influenced $(P<0.001)$ the SP MLT concentration, demonstrating that the ejaculates collected during the increasing day length period exhibited reduced MLT concentrations compared with those collected during the decreasing day length period (Fig. 1).

\section{Experiment 2: Variability of Seminal Plasma Melatonin Concentration among Boars, Ejaculates, and Ejaculate Portions}

The SP concentration of MLT differed $(P<0.001)$ among boars (interboar variability) and ejaculates within boar (intraboar variability; Fig. 2). The interboar variability $(F$-values $=140.04, \mathrm{df}=20)$ was

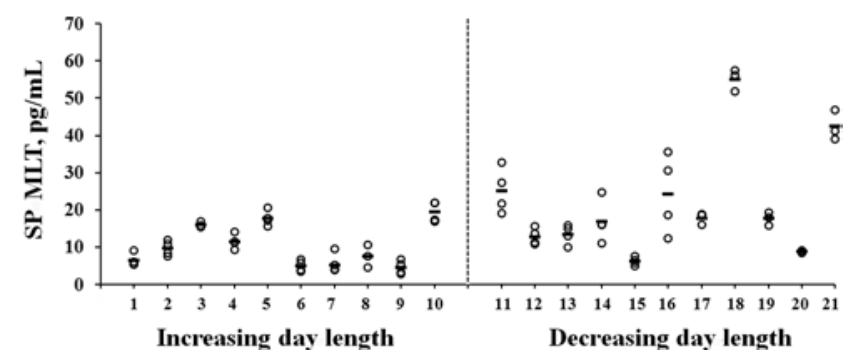

Figure 2. Scatterplot showing the concentration of melatonin (MLT) in seminal plasma (SP) of entire boar ejaculates collected during increasing (10 boars and 4 ejaculates per boar) and decreasing (11 boars and 4 ejaculates per boar) day length period. Circles indicate the SP MLT concentration measured in each ejaculate, and the lines indicate the mean for each boar.

considerably increased compared with the intraboar variability $(F$-values $=5.65, \mathrm{df}=57)$. The $\mathrm{ICC}$ score was 0.92 (95\% confidence interval [CI] 0.82-0.97), indicating excellent consistency in the measurements of the SP MLT concentration among ejaculates within boar. The intraboar variability was reduced during the increasing day length period (ICC score of 0.97; 95\% CI 0.92-0.99) compared with the decreasing day length period (ICC score of 0.83 ; 95\% CI 0.39-0.97).

The SP MLT concentration also varied $(P<0.001)$ among ejaculate portions (Fig. 3). The interaction of boar $\times$ ejaculate portions was significant $(P<0.001)$, as boars exhibited different patterns of variation. Despite this, most boars exhibited a similar pattern of variation that was characterized by the lowest and the greatest MLT concentrations in the SP samples from the first $10 \mathrm{~mL}$ of the $\mathrm{SRF}$ and post-SRF, respectively.

\section{Experiment 3: Relationship between Seminal Plasma Melatonin Concentration and Quality and Sperm Functionality of Liquid-Stored Semen AI Doses}

The SP MLT concentration differed among ejaculates, ranging from 2.12 to $73.66 \mathrm{pg} / \mathrm{mL}$. The ejaculates were classified (hierarchical clustering; $P<0.001$ ) into 2 groups: high (from 26.14 to $73.66 \mathrm{pg} / \mathrm{mL} ; n=15$ ) or low (from 2.12 to $20.41 \mathrm{pg} / \mathrm{mL} ; n=15$ ) SP concentration of MLT. Sperm quality, in terms of total sperm motility, progressive sperm motility, and sperm viability, did not differ between the 2 SP MLT groups at any storage time. The total and progressive sperm motility decreased $(P<0.001)$ across storage time regardless of SP MLT group, and the decrease was particularly evident between 72 and $144 \mathrm{~h}$ of storage (Table 1).

Intracellular $\mathrm{H}_{2} \mathrm{O}_{2}$ generation (positive to $\mathrm{H}_{2}$ DCFDA), total $\mathrm{O}_{2}^{-}$production (positive to DHE), and lipid peroxidation (positive to BODIPY) in viable sperm did not differ between the 2 SP MLT groups. In contrast, mitochondrial $\mathrm{O}_{2}^{-}$production (positive to MSR) was lower $(P<0.001)$ in the viable sperm of the AI semen samples from ejaculates with high SP MLT concentration 


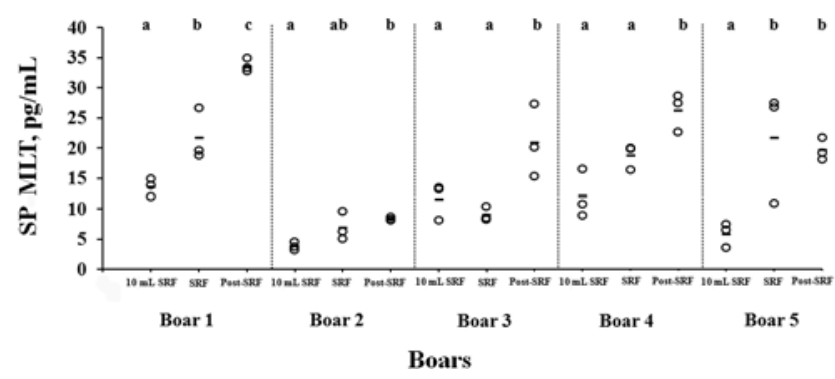

Figure 3. Scatterplot showing the concentration of melatonin (MLT) present in the seminal plasma (SP) from 3 portions of boar ejaculate (5 boars and 3 ejaculates per boar): the first $10 \mathrm{~mL}$ of sperm-rich ejaculate fraction (SRF) and the remaining SRF and the post-SRF. Circles indicate the SP MLT concentration measured in each ejaculate, and the line indicate the mean for each portion. ${ }^{\mathrm{a}-\mathrm{c}}$ Different superscripts indicate significant differences $(P<0.001)$ among ejaculate portions.

(Table 1). Total $\mathrm{O}_{2}^{-}$production, mitochondrial $\mathrm{O}_{2}^{-}$production, and lipid peroxidation differed $(P<0.005)$ across storage times regardless of the SP MLT group (Table 1).

\section{Experiment 4: Relationship between Seminal Plasma Melatonin Concentration and In Vivo Fertility of Liquid-Stored Semen AI Doses}

The 14 AI boars were classified (hierarchical clustering; $P<0.001)$ into 2 groups having high (84.4 to $90.4 \% ; n=10)$ or low $(76.7$ to $81.7 \% ; n=4)$ percentages of farrowing rates. No differences in SP MLT were identified between the boar groups (Fig. 4A). The same 14 AI boars were also classified (hierarchical clustering; $P<0.001)$ into 2 groups with large (14.7 to 16.2 piglets born per litter; $n=8$ ) or small (12.5 to 13.8 piglets born per litter; $n=6$ ) litter sizes. The SP MLT concentration did not differ between the boar groups (Fig. 4B).

\section{DISCUSSION}

To the best of our knowledge, this study is the first one focused on evaluating biological profile and functional roles of SP MLT in livestock sires, particularly boars, used in commercial AI programs. The average SP MLT concentrations found in the present study were like those recently found by González-Arto et al. (2016b) and close to those previously observed by Andersson (2001) in blood plasma samples collected from adult boars during daylight hours. The first noteworthy finding was the significant variability in the concentration of MLT among SP samples, which agrees with previous results achieved by González-Arto et al. (2016b) in SP samples of different livestock males. Analyzing the factors causing this variability, the present study provides evidence of seasonality in the level of boar SP MLT concentration, as the ejaculates collected during the decreasing day length period exhibited the greatest concentrations. This seasonal pattern agrees with that observed by Tast et al.

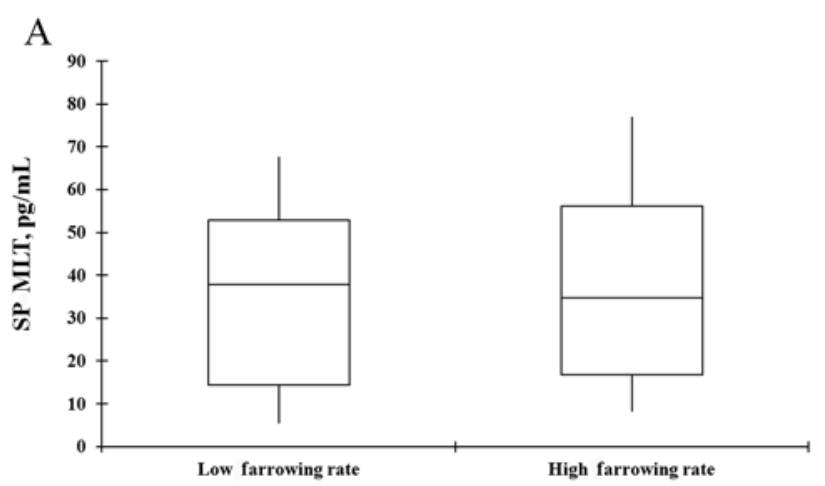

B

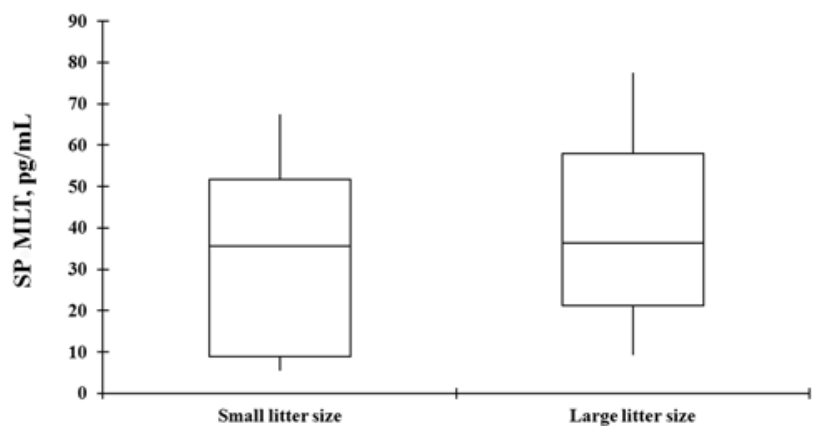

Figure 4. Box-and-whisker plot showing the concentration of melatonin (MLT) present in the seminal plasma (SP) of entire ejaculates collected of boars used in AI programs and hierarchically grouped $(P<0.001)$ with (A) high $(84.4$ to $90.4 \% ; n=10)$ or low $(76.7$ to $81.7 \% ; n=4)$ farrowing rates and (B) large (14.7 to 16.2 piglets born per litter; $n=8$ ) or small (12.5 to 13.8 piglets born per litter; $n=6$ ) litter sizes.

(2001a) in serum MLT levels of wild boars. The existence of a seasonal pattern in SP MLT concentration in ejaculates of AI boars, like that showed by rams, a typical seasonal breeder (Casao et al., 2010a), was particularly noticeable because the domestic boar is not considered a typical seasonal breeder. Currently, we do not find a convincing explanation for these findings, as seasonal differences in light conditions do not seem to be the reason. The boars used in this study were housed in AI centers with temperature- and lighting-controlled climate rooms under a constant photoperiod of $16 \mathrm{~h}$ of light per day, as required by European Union rules. Furthermore, higher light intensities than those used in herein $(150 \mathrm{~lx})$ have not been shown to modify the pineal secretion pattern of MLT in pigs (Tast et al., 2001b). However, it should be noted that the barns had windows and the boars might have been able to detect changes in outdoor daylight. To elucidate concerns about endogenous SP MLT rhythms in AI boars requires further studies using different approaches than that of the present study.

In addition to season, other factors of variation in SP MLT concentrations were identified, specifically the individual, the ejaculate within boar, and the portion within the ejaculate, which were expected, as they were previously noted to influence other SP compo- 
Table 1. Sperm quality and functionality of 30 liquid AI semen doses $\left(2,500 \times 10^{6} \mathrm{sperm} /\right.$ dose $)$ stored for $144 \mathrm{~h}$ at 15 to $17^{\circ} \mathrm{C}$ from boar ejaculates hierarchically grouped as high (from 26.14 to $73.66 \mathrm{pg} / \mathrm{mL} ; n=15$ ) and low ( 2.12 to $20.41 \mathrm{pg} / \mathrm{mL} ; n=15$ ) melatonin (MLT) concentrations in seminal plasma (SP)

\begin{tabular}{|c|c|c|c|c|}
\hline \multirow[b]{2}{*}{ Sperm parameters, $\%$} & \multirow{2}{*}{$\begin{array}{c}\text { SP MLT } \\
\text { concentration }\end{array}$} & \multicolumn{3}{|c|}{ Storage time of AI doses at 15 to $17^{\circ} \mathrm{C}, \mathrm{h}$} \\
\hline & & 24 & 72 & 144 \\
\hline \multirow[t]{2}{*}{ Total sperm motility } & Low & $78.2 \pm 3.28^{\mathrm{a}}$ & $72.73 \pm 3.98^{b}$ & $55.53 \pm 7.39^{\mathrm{c}}$ \\
\hline & High & $82.73 \pm 1.39^{\mathrm{a}}$ & $77.00 \pm 1.91^{\mathrm{b}}$ & $43.33 \pm 8.15^{\mathrm{c}}$ \\
\hline \multirow[t]{2}{*}{ Progressive sperm motility } & Low & $44.93 \pm 3.95^{\mathrm{a}}$ & $47.6 \pm 3.89^{\mathrm{a}}$ & $34.47 \pm 6.33^{b}$ \\
\hline & High & $44.00 \pm 3.35^{\mathrm{a}}$ & $46.73 \pm 3.25^{\mathrm{a}}$ & $27.27 \pm 5.57^{b}$ \\
\hline \multirow[t]{2}{*}{ Sperm viability } & Low & $89.40 \pm 1.25$ & $87.95 \pm 1.90$ & $89.06 \pm 1.66$ \\
\hline & High & $88.80 \pm 1.03$ & $88.77 \pm 1.28$ & $85.89 \pm 2.45$ \\
\hline \multirow{2}{*}{ Viable sperm $\mathrm{H}_{2}$ DCFDA positive ${ }^{1}$} & Low & $66.41 \pm 2.83$ & $59.16 \pm 5.04$ & $63.62 \pm 15.74$ \\
\hline & High & $64.27 \pm 4.21$ & $56.15 \pm 5.70$ & $59.97 \pm 4.71$ \\
\hline \multirow[t]{2}{*}{ Viable sperm MSR positive ${ }^{2}$} & Low & $50.41 \pm 9.81^{\mathrm{a} *}$ & $47.56 \pm 9.11^{\mathrm{a} *}$ & $70.09 \pm 8.35^{\mathrm{b} *}$ \\
\hline & High & $18.11 \pm 3.30^{\mathrm{a}} \dagger$ & $18.65 \pm 4.38^{\mathrm{a}} \dagger$ & $52.65 \pm 8.50^{\mathrm{b}} \dagger$ \\
\hline \multirow[t]{2}{*}{ Viable sperm DHE positive ${ }^{3}$} & Low & $56.43 \pm 8.92^{\mathrm{a}}$ & $67.98 \pm 10.93^{\mathrm{a}}$ & $91.34 \pm 1.40^{\mathrm{b}}$ \\
\hline & High & $58.97 \pm 8.80^{\mathrm{a}}$ & $65.49 \pm 11.13^{\mathrm{a}}$ & $87.00 \pm 3.22^{b}$ \\
\hline \multirow[t]{2}{*}{ Viable sperm BODIPY positive ${ }^{4}$} & Low & $0.53 \pm 0.14^{\mathrm{a}}$ & $0.73 \pm 0.20^{\mathrm{b}}$ & $1.00 \pm 0.18^{\mathrm{c}}$ \\
\hline & High & $0.34 \pm 0.07^{\mathrm{a}}$ & $0.69 \pm 0.22^{\mathrm{b}}$ & $1.26 \pm 0.36^{\mathrm{c}}$ \\
\hline
\end{tabular}

${ }^{\mathrm{a}-\mathrm{c}}$ Different superscripts indicate differences $(P<0.005)$ among storage times within the same SP MLT concentration.

${ }^{*}, \dagger$ ifferent symbols indicate differences $(P<0.001)$ among SP MLT concentrations.

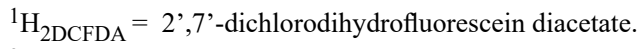

${ }^{2} \mathrm{MSR}=$ MitoSOX Red; viable sperm with mitochondria generation of $\mathrm{O}_{2}{ }^{-}$

${ }^{3} \mathrm{DHE}=$ dihydroethidium; viable sperm generating intracellular $\mathrm{O}_{2}^{-}$.

${ }^{4} \mathrm{BODIPY}=\mathrm{C} 11$ Boron-dipyrromethene $581 / 591=$ viable sperm showing lipid peroxidation

nents (Strzezek et al., 2005; Barranco et al., 2015, 2016). Differences among boars could have been ascribed to the genetic origin that was more closely related to individuals than to breed (Thurston et al., 2001). It is remarkable that the differences among ejaculates within the same boar were greater in the ejaculates collected during the decreasing day length period, which would support the theory that other factors beyond day length itself would be responsible for the increase in MLT concentration during the decreasing day length period. The impact of these factors would vary from boar to boar, regardless of breed or handling management. It is worth noting that SP from SRF and particularly that from the first $10 \mathrm{~mL}$ exhibited reduced MLT concentrations compared with the concentrations from post-SRF in most of the examined boars. This may suggest that seminal vesicles would be the accessory glands that could contribute more in SP MLT, as their secretion is the largest contributor to SP of post-SRF (Rodríguez-Martinez et al., 2011).

In addition to the existence of a seasonal pattern, the occurrence of the greatest concentrations of SP MLT in the ejaculates collected during the decreasing day length period was also especially noticeable, as boar ejaculates collected during this period of the year usually show the worst sperm quality (Sancho et al., 2004; Barranco et al., 2013). Accordingly, the third experiment was conducted to identify the putative relationship between the SP MLT and quality and sperm functionality of boar AI semen samples. No relationship between the concentration of SP
MLT and sperm quality, measured in terms of sperm motility and viability, was identified. This result was not surprising, as controversy exists regarding the relationship between SP MLT and sperm quality. This relationship, specifically with sperm motility, was previously evaluated only in ejaculates of men, showing disparate results, including negative (Yie et al., 1991), positive (Awad et al., 2006), or no relationship whatsoever (Bornman et al., 1989; Luboshitzky et al., 2002). In livestock species, the only report about the influence of MLT on sperm quality includes some experimental studies where exogenous MLT was added to extended semen. These studies also produced inconsistent results. Jang et al. (2010) and Ashrafi et al. (2011) found that the addition of MLT to semen extender improved both motility and sperm viability of boar and ram semen samples, respectively. Conversely, Martín-Hidalgo et al. (2011) and Tanyildizi et al. (2006) found that added MLT reduced the percentage of motile sperm in boar and bull semen samples, respectively. None of the above studies provided logical explanations for the results. The inconsistent results among reports may be due, in part, to differences in either experimental approach and/or the MLT concentrations used, as opposite effects on sperm quality were reported depending on the MLT concentration used (Casao et al., 2010b). Sperm functionality in terms of oxidative stress was also evaluated in the present study given that MLT is a powerful antioxidant able to either inhibit the generation or neutralize the activity of reactive oxygen species (ROS; Bonnefont- 
Rousselot and Collin, 2010; Reiter et al., 2016). Our findings showed a negative relationship between the SP MLT and generation of $\mathrm{O}_{2}^{-}$by mitochondria of viable sperm. Mitochondria are the major site of ROS generation in sperm, and $\mathrm{O}_{2}{ }^{-}$is the main ROS synthesized, which represents the first link in the synthesis pathway of another ROS (Aitken et al., 2012). Reactive oxygen species can play a positive or negative role in sperm quality depending on their concentration (Aitken et al., 2012). Physiological low levels of $\mathrm{O}_{2}{ }^{-}$are essential for sperm performance, including motility, whereas pathological high levels are detrimental to sperm performance, including motility (Koppers et al., 2008). Melatonin attenuates mitochondrial $\mathrm{O}_{2}^{-}$production when generated in excess (Jou et al., 2004) or when the concentration of MLT is also in excess (Gavella and Lipovac, 2000). These 2 circumstances would not occur in the semen samples evaluated in the present study given that both mitochondrial $\mathrm{O}_{2}{ }^{-}$production and SP MLT concentration were broadly within the physiological ranges, which is consistent with sires selected for semen donors. Consequently, the lack of a relationship between SP MLT and sperm quality in sires used in AI programs would be expected.

The last experiment evaluated the possible relationship between the concentration of SP MLT in the ejaculates and fertility outcome of semen AI doses elaborated from the ejaculates. Previous reports indicate that once placed in the female genital tract, SP MLT together with MLT secreted in the female genital tract would play a relevant role in the reproductive tract inflammatory response, contributing to sperm selection and, consequently, facilitating fertilization (Brzezinski et al., 1987; Nakamura et al., 2003). Furthermore, MLT had a positive effect on in vitro embryo development when added at concentrations of $23 \mathrm{ng} / \mathrm{mL}$ to $232 \mu \mathrm{g} / \mathrm{mL}$ to the diluents used to extend bull (Papis et al., 2007; Pang et al., 2016) or boar (Jang et al., 2010) semen. However, the above positive effects of MLT would be concentration dependent and more difficult to assess in vivo than in vitro because SP concentration of MLT is usually relatively low (Gavella and Lipovac, 2000). Accordingly, the present study was performed with ejaculates collected during the decreasing day length period, as these samples exhibited greater and more variable SP MLT concentrations. In addition, the expected boar differences on fertility outcome could also be more variable, as shown by Sancho et al. (2004). The results demonstrated that SP MLT concentration was not related to the percentage of farrowing or litter size. Like sperm quality, there is also controversy in the literature about the putative relationship between SP MLT and male fertility, as both are negatively and positively related to fertility in men (Yie et al., 1991; Awad et al., 2006). These contradictory results in the relationship between SP MLT and fertility could be related to
SP MLT concentration, which is highly variable among individuals, regardless of the species, and lower in pigs, on average, compared with other species, such as sheep (Casao et al., 2010a), cattle (González-Arto et al., 2016b), or humans (Awad et al., 2006).

\section{Conclusions}

In summary, the present study demonstrated that the SP concentration of MLT in boar ejaculates differs among the seasons of ejaculate collection, showing those collected in the decreasing day length period have the greatest concentrations. The current study also indicated that the concentration of MLT in SP also varies depending on the boar, the ejaculate within boar, and even the portion within the ejaculate. Furthermore, the results revealed that the SP concentration of MLT of boar ejaculates was not related to either sperm quality or fertility outcome of semen AI doses from the ejaculates, even though SP MLT exhibited antioxidant activity attenuating mitochondrial $\mathrm{O}_{2}{ }^{-}$production in viable sperm.

\section{LITERATURE CITED}

Aitken, R. J., K. T. Jones, and S. A. Robertson. 2012. Reactive oxygen species and sperm function in sickness and in health. J. Androl. 33:1096-1106. doi:10.2164/jandrol.112.016535

Andersson, H. 2001. Plasma melatonin levels in relation to the lightdark cycle and parental background in domestic pigs. Acta Vet. Scand. 42:287-294. doi:10.1186/1751-0147-42-287

Ashrafi, I., H. Kohram, H. Naijian, M. Bahreini, and M. Poorhamdollah. 2011. Protective effect of melatonin on sperm motility parameters on liquid storage of ram semen at $5^{\circ} \mathrm{C}$. Afr. J. Biotechnol. 10:6670-6674.

Awad, H., F. Halawa, T. Mostafa, and H. Atta. 2006. Melatonin hormone profile in infertile males. Int. J. Androl. 29:409-413. doi:10.1111/j.1365-2605.2005.00624.x

Barranco, I., M. D. Ortega, M. J. Martinez-Alborcia, J. M. Vazquez, E. A. Martinez, and J. Roca. 2013. Season of ejaculate collection influences the freezability of boar spermatozoa. Cryobiology 67:299-304. doi:10.1016/j.cryobiol.2013.09.001

Barranco, I., A. Tvarijonaviciute, C. Perez-Patiño, D. V. Alkmin, J. J. Ceron, E. A. Martinez, H. Rodríguez-Martinez, and J. Roca. 2015. The activity of paraoxonase type 1 (PON-1) in boar seminal plasma and its relationship with sperm quality, functionality, and in vivo fertility. Andrology 3:315-320. doi:10.1111/andr.309

Barranco, I., A. Tvarijonaviciute, C. Perez-Patiño, A. Vicente-Carrillo, I. Parrilla, J. J. Ceron, E. A. Martinez, H. Rodriguez-Martinez, and J. Roca. 2016. Glutathione peroxidase 5 is expressed by the entire pig male genital tract and once in the seminal plasma contributes to sperm survival and in vivo fertility. PLoS One 11:e0162958. doi:10.1371/journal.pone.0162958

Bonnefont-Rousselot, D., and F. Collin. 2010. Melatonin: Action as antioxidant and potential applications in human disease and aging. Toxicology 278:55-67. doi:10.1016/j.tox.2010.04.008

Bornman, M. S., J. M. Oosthuizen, H. C. Barnard, G. W. Schulenburg, D. Boomker, and S. Reif. 1989. Melatonin and sperm motility. Andrologia 21:483-485. doi:10.1111/j.1439-0272.1989. tb02456.x 
Broekhuijse, M. L., E. Šoštarić, H. Feitsma, and B. M. Gadella. 2012. Relationship of flow cytometric sperm integrity assessments with boar fertility performance under optimized field conditions. J. Anim. Sci. 90:4327-4336. doi:10.2527/jas.2012-5040

Brzezinski, A., M. M. Seibel, H. J. Lynch, M. H. Deng, and R. J. Wurtman. 1987. Melatonin in human preovulatory follicular fluid. J. Clin. Endocrinol. Metab. 64:865-867. doi:10.1210/ jcem-64-4-865

Casao, A., I. Cebrian, M. E. Asumpção, R. Perez-Pe, J. A. Abecia, F. Forcada, J. A. Cebrian-Perez, and T. Muiño-Blanco. 2010a. Seasonal variations of melatonin in ram seminal plasma are correlated to those of testosterone and antioxidant enzymes. Reprod. Biol. Endocrinol. 8:59. doi:10.1186/1477-7827-8-59

Casao, A., N. Mendoza, R. Perez-Pe, P. Grasa, J. A. Abecia, F. Forcada, J. A. Cebrián-Pérez, and T. Muino-Blanco. 2010b. Melatonin prevents capacitation and apoptotic-like changes of ram spermatozoa and increases fertility rate. J. Pineal Res. 48:39-46. doi:10.1111/j.1600-079X.2009.00722.x

European Parliament and the Council of the European Union. 2010. EU Directive 2010/63/EU of the European Parliament and of the Council of 22 September 2010 on the protection of animals used for scientific purposes. http://eur-lex.europa.eu/legal-content/ EN/TXT/PDF/?uri=CELEX:32010L0063\&from=EN

Gavella, M., and V. Lipovac. 2000. Antioxidative effect of melatonin on human spermatozoa. Arch. Androl. 44:23-27. doi:10.1080/014850100262371

González-Arto, M., T. R. Hamilton, M. Gallego, E. Gaspar-Torrubia, D. Aguilar, E. Serrano-Blesa, J. A. Abecia, R. Pérez-Pé, T. Muiño-Blanco, J. A. Cebrián-Pérez, and A. Casao. 2016a. Evidence of melatonin synthesis in the ram reproductive tract. Andrology 4:163-171. doi:10.1111/andr. 12117

González-Arto, M., A. Vicente-Carrillo, F. Martinez-Pastor, E. Fernández-Alegre, J. Roca, J. Miró, T. Rigau, J. E. RodríguezGil, R. Pérez-Pé, T. Muiño-Blanco, J. A. Cebrián-Pérez, and A. Casao. 2016b. Melatonin receptors MT1 and MT2 are expressed in spermatozoa from several seasonal and nonseasonal breeder species. Theriogenology 86:1958-1968. doi:10.1016/j. theriogenology.2016.06.016.

Jang, H. Y., Y. H. Kim, B. W. Kim, I. C. Park, H. T. Cheong, J. T. Kim, C. K. Park, H. S. Kong, H. K. Lee, and B. K. Yang. 2010. Ameliorative effects of melatonin against hydrogen peroxideinduced oxidative stress on boar sperm characteristics and subsequent in vitro embryo development. Reprod. Domest. Anim. 45:943-950. doi:10.1111/j.1439-0531.2009.01466.x

Jou, M. J., T. I. Peng, R. J. Reiter, S. B. Jou, H. Y. Wu, and S. T. Wen 2004. Visualization of the antioxidative effects of melatonin at the mitochondrial level during oxidative stress-induced apoptosis of rat brain astrocytes. J. Pineal Res. 37:55-70. doi:10.1111/ j.1600-079X.2004.00140.x

Karaaslan, C., and S. Suzen. 2015. Antioxidant properties of melatonin and its potential action in diseases. Curr. Top. Med. Chem. 15:894-903. doi:10.2174/1568026615666150220120946

Koppers, A. J., G. N. De Iuliis, J. M. Finnie, E. A. McLaughlin, and R. J. Aitken. 2008. Significance of mitochondrial reactive oxygen species in the generation of oxidative stress in spermatozoa. J. Clin. Endocrinol. Metab. 93:3199-3207. doi:10.1210/jc.2007-2616

Luboshitzky, R., Z. Shen-Orr, and P. Herer. 2002. Seminal plasma melatonin and gonadal steroids concentrations in normal men Arch. Androl. 48:225-232. doi:10.1080/01485010252869324

Martín-Hidalgo, D., F. J. Barón, M. J. Bragado, P. Carmona, A. Robina, L. J. García-Marín, and M. C. Gil. 2011. The effect of melatonin on the quality of extended boar semen after long-term storage at $17^{\circ} \mathrm{C}$. Theriogenology $75: 1550-1560$. doi:10.1016/j. theriogenology.2010.12.021
Nakamura, Y., H. Tamura, H. Takayama, and H. Kato. 2003. Increased endogenous level of melatonin in preovulatory human follicles does not directly influenced progesterone production. Fertil. Steril. 80:1012-1016. doi:10.1016/S0015-0282(03)01008-2

Novak, S., A. Ruiz-Sánchez, W. T. Dixon, G. R. Foxcroft, and M. K. Dyck. 2010. Seminal plasma proteins as potential markers of relative fertility in boars. J. Androl. 31:188-200. doi:10.2164/ jandrol.109.007583

Pang, Y. W., Y. Q. Sun, X. L. Jiang, Z. Q. Huang, S. J. Zhao, W. H. Du, H. S. Hao, X. M. Zhao, and H. B. Zhu. 2016. Protective effects of melatonin on bovine sperm characteristics and subsequent in vitro embryo development. Mol. Reprod. Dev. 83:993-1002. doi: $10.1002 / \mathrm{mrd} .22742$

Papis, K., O. Poleszczuk, E. Wenta-Muchalska, and J. A. Modlinski. 2007. Melatonin effect on bovine embryo development in vitro in relation to oxygen concentration. J. Pineal Res. 43:321-326. doi:10.1111/j.1600-079X.2007.00479.x

Reiter, R. J., J. R. Calvo, M. Karbownik, W. Qi, and D. X. Tan. 2000. Melatonin and its relation to the immune system and inflammation. Ann. N. Y. Acad. Sci. 917:376-386. doi:10.1111/j.1749-6632.2000.tb05402.x

Reiter, R. J., J. C. Mayo, D. X. Tan, R. M. Sainz, M. Alatorre-Jimenez, and L. Qin. 2016. Melatonin as an antioxidant: Under promises but over delivers. J. Pineal Res. 61:253-278. doi:10.1111/ jpi. 12360

Reiter, R. J., D. X. Tan, L. C. Manchester, S. D. Paredes, J. C. Mayo, and R. M. Sainz. 2009. Melatonin and reproduction revisited. Biol. Reprod. 81:445-456. doi:10.1095/biolreprod.108.075655

Rodríguez-Martinez, H., U. Kvist, J. Ernerudh, L. Sanz, and J. J. Calvete. 2011. Seminal plasma proteins: What role do they play? Am. J. Reprod. Immunol. 66:11-22. doi:10.1111/j.16000897.2011.01033.x

Sancho, S., E. Pinart, M. Briz, N. Garcia-Gil, E. Badia, J. Bassols, E. Kádár, A. Pruneda, E. Bussalleu, M. Yeste, M. G. Coll, and S. Bonet. 2004. Semen quality of postpubertal boars during increasing and decreasing natural photoperiods. Theriogenology 62:1271-1282. doi:10.1016/j.theriogenology.2004.01.003

Silva, P. F., and B. M. Gadella. 2006. Detection of damage in mammalian sperm cells. Theriogenology 65:958-978. doi:10.1016/j. theriogenology.2005.09.010

Strzezek, J., P. Wysocki, W. Kordan, M. Kuklinska, M. Mogielnicka, D. Soliwoda, and L. Fraser. 2005. Proteomics of boar seminal plasma- current studies and possibility of their application in biotechnology of animal reproduction. Reprod. Biol. 5:279-290.

Tanyildizi, S., T. Bozkurt, O. Üftu, and F. Sakun. 2006. In vitro effects of melatonin on hyaluronidase activity and sperm motility in bull semen. Turk. J. Vet. Anim. Sci. 30:89-93.

Tast, A., O. Hälli, S. Ahlström, H. Andersson, R. J. Love, and A. Peltoniemi. 2001a. Seasonal alterations in circadian melatonin rhythms of the European wild boar and domestic gilt. J. Pineal Res. 30:43-49. doi:10.1034/j.1600-079X.2001.300106.x

Tast, A., R. J. Love, G. Evans, H. Andersson, O. A. Peltoniemi, and D. J. Kennaway. 2001b. The photophase light intensity does not affect the scotophase melatonin response in the domestic pig. Anim. Reprod. Sci. 65:283-290. doi:10.1016/S03784320(01)00077-X

Thurston, L. M., P. F. Watson, A. J. Mileham, and W. V. Holt. 2001 Morphologically distinct sperm subpopulations defined by Fourier shape descriptors in fresh ejaculates correlate with variation in boar semen quality following cryopreservation. J. Androl. 22:382-394.

Van Vuuren, R. J., D. J. Du Plessis, and J. J. Theron. 1988. Melatonin in human semen. S. Afr. Med. J. 73:375-376.

Yie, S. M., S. Daya, G. M. Brown, L. Deys, E. V. YoungLai. 1991. Melatonin and aromatase stimulating activity of human seminal plasma. Andrologia 23:227-231. doi:10.1111/j.1439-0272.1991. tb02543. $x$ 